\title{
Measurement of Lung Diffusion and Cardiac Output with a Single Breath Gas Absorption Method During Graded Exercise Testing: Reference Values for Clinical Testing
}

\author{
Albert Miller ${ }^{*}, 1$, Maqbool Murtuza ${ }^{2}$ and Thomas E. Bachman ${ }^{3}$ \\ ${ }^{I}$ Center for Biology of Natural Systems, Queens College, City University of New York, Flushing, NY, USA \\ ${ }^{2}$ St. Francis Hospital, Poughkeepsie, New York, USA \\ ${ }^{3}$ California State University, San Bernardino, San Bernardino, California, USA
}

\begin{abstract}
Measurement of lung diffusion and cardiac output with a single breath gas absorption method during graded exercise testing: reference values for clinical testing.

Objective: The evaluation of ventilation and gas exchange has become a standard part of clinical exercise testing. We sought to assess the practicality of integrating measurements of lung diffusion for carbon monoxide $\left(\mathrm{D}_{\mathrm{L}} \mathrm{CO}\right)$ and noninvasive cardiac output (using pulmonary capillary blood flow $\mathrm{Q}_{\mathrm{C}}$ ) into our clinical graded exercise tests. Our objective was to define the responses in normal subjects so that impairment could be detected in patients suspected of having pulmonary or pulmonary vascular disease despite normal resting $\mathrm{D}_{\mathrm{L}} \mathrm{CO}$ and $\mathrm{Q}_{\mathrm{C}}$. We conducted incremental exercise tests on 20 normal volunteers at 6 levels of exercise ranging between rest and $75 \%$ of their measured maximum. The investigational method is based on absorption of $\mathrm{CO}$ (for $\mathrm{D}_{\mathrm{L}} \mathrm{CO}$ ) and acetylene (for $\mathrm{Q}_{\mathrm{C}}$ ) into the pulmonary circulation during a single slow exhalation. The subjects averaged 35 years of age with a maximum work capacity of $76 \%$ of predicted maximum.

Results: The values increased linearly with workload $\left(\mathrm{Q}_{\mathrm{C}}\right.$ in $\mathrm{L} / \mathrm{min}=3.5+6.5 * \mathrm{VO}_{2}$ in $\mathrm{L} / \mathrm{min}$, and $\mathrm{D}_{\mathrm{L}} \mathrm{CO}$ in $\mathrm{ml} / \mathrm{min} / \mathrm{mmHg}=18.7+10.2 * \mathrm{VO}_{2}$ in $\left.\mathrm{L} / \mathrm{min}\right)$. From baseline levels the $\mathrm{Q}_{\mathrm{C}}$ increased more than two-fold and the $\mathrm{D}_{\mathrm{L}} \mathrm{CO}$ increased by $50 \%$. The mean deviation of individual measurements from the patient's regressed response was $9.9 \%$ and $6.6 \%$ respectively.

Conclusions: We found the procedure easy to include in our standard graded exercise protocol and the single breath technique readily performed. Normative values were obtained for measurements expressed as a percentage of individual maximum and as actual $\mathrm{VO}_{2}$. At a moderate level of exercise $\left(\mathrm{VO}_{2} 1.0\right.$ liter) the $\mathrm{D}_{\mathrm{L}} \mathrm{CO}$ and $\mathrm{Q}_{\mathrm{C}}$ should increase at least $20 \%$ and $65 \%$ respectively above baseline. Since the response of $\mathrm{Q}_{c}$ and $\mathrm{D}_{\mathrm{L}} \mathrm{CO}$ to progressive exercise offers pathophysiological information of clinical interest, its application can now be characterized in patients with different disorders including those with normal resting $\mathrm{Q}_{\mathrm{c}}$ and $\mathrm{D}_{\mathrm{L}} \mathrm{CO}$.
\end{abstract}

Keywords: Cardiopulmonary exercise testing, diffusing capacity of the lung, cardiac output, single breath gas absorption, pulmonary capillary blood flow.

\section{INTRODUCTION}

The concept of evaluating the integrated responses of ventilation, circulation and skeletal muscle to exercise is well accepted $[1,2]$. During graded exercise testing (GXT), measurements of heart rate, ECG rhythm/morphology, ventilation, metabolic responses and gas exchange are now standard. Measurements of cardiac output and lung diffusion $\left(\mathrm{D}_{\mathrm{L}} \mathrm{CO}\right)$ during GXT would be of great interest but are far less frequent because of technical difficulties. Cardiac output is frequently measured before and after many therapeutic interventions, usually by invasive techniques. Pulmonary capillary blood flow $\left(\mathrm{Q}_{\mathrm{C}}\right)$ is similar to cardiac output in the

*Address correspondence to this author at the Center for Biology of Natural Systems, Queens College, City University of New York, 163-03 Horace Harding Expressway, Flushing, NY 11365, USA;

E-mail: almillermd@gmail.com absence of cardiac or pulmonary anatomical shunts. An easily performed non-invasive estimate of $\mathrm{Q}_{\mathrm{C}}$ during graded exercise would be well suited to serial studies of patients treated medically for heart failure or after surgical procedures including left ventricular assist and heart transplant. Evaluation of the expected increase of $\mathrm{D}_{\mathrm{L}} \mathrm{CO}$ with exercise can illuminate the mechanism for exercise intolerance in patients with normal or near normal $\mathrm{D}_{\mathrm{L}} \mathrm{CO}$ at rest. This is a common problem in pulmonary and occupational medicine. In two large groups of patients with minimal interstitial lung disease (asbestosis [3] and sarcoidosis [4]) studies by the senior author found failure to decrease deadspace ventilation during GXT to be the most sensitive indicator of disease. This requires an arterial line and serial sampling during progressively more intense exercise. Serial non-invasive measurements of $\mathrm{D}_{\mathrm{L}} \mathrm{CO}$, demonstrating failure to recruit and expand the pulmonary capillary bed, would be similarly useful. Studies of $\mathrm{Q}_{\mathrm{C}}$ and 
$\mathrm{D}_{\mathrm{L}} \mathrm{CO}$ during GXT have suggested their promise as prognostic indicators [5-8].

A steady exhalation single breath method for measuring $\mathrm{Q}_{\mathrm{C}}$ and $\mathrm{D}_{\mathrm{L}} \mathrm{CO}$ is commercially available as a research tool (SensorMedics Vmax System, Yorba Linda, California). The integration of these measurements into a system used for graded cardiopulmonary exercise testing suggested the possibility of measuring changes in $\mathrm{Q}_{\mathrm{C}}$ and $\mathrm{D}_{\mathrm{L}} \mathrm{CO}$ throughout a standard GXT. Most single breath measurements of $\mathrm{Q}_{\mathrm{C}}$ and $\mathrm{D}_{\mathrm{L}} \mathrm{CO}$ have been made in steady state exercise. One such study tested subjects during successive stages following return to baseline, but two to three days were necessary to complete each study [9].

To evaluate this feasibility, GXTs using a bicycle ergometer were conducted incorporating the $\mathrm{Q}_{\mathrm{C}}$ and $\mathrm{D}_{\mathrm{L}} \mathrm{CO}$ measurements along with traditional ventilatory and gas exchange parameters in 20 normal volunteers. The increases in $\mathrm{Q}_{\mathrm{C}}$ and $\mathrm{D}_{\mathrm{L}} \mathrm{CO}$ at progressive workloads (expressed both as a percentage of maximum $\mathrm{VO}_{2}$ and as $\mathrm{VO}_{2}$ in $\mathrm{L} / \mathrm{min}$ at standard levels) in these normal subjects provide guidelines for assessing these responses in patients.

\section{MATERIALS AND METHODS}

\section{Description of Technique}

The "intrabreath" (IB) method employed in this study has been compared to invasive methods [10-12] and its use demonstrated during steady state exercise [9, 13, 14] and ramp protocols [15]. The IB technique measures the absorption of acetylene (for $\mathrm{Q}_{\mathrm{C}}$ ) and carbon monoxide (for $\mathrm{D}_{\mathrm{L}} \mathrm{CO}$ ) continuously, using a rapid response infra-red analyzer, during a single steady exhalation. Readings are normalized for lung volume with the use of a third, inert gas, methane. The calculations are based on gas measurements from the alveolar plateau of exhalation, which is clearly demonstrated with the rapid gas analyzer. This single breath method does not require a breath hold. Exhalation following a full inhalation must be maintained at a steady flow of less than $1 \mathrm{~L} / \mathrm{sec}$ for greater than 3 seconds after clearing the dead space (Fig. 1). This is accomplished by proper coaching and the use of a slight expiratory resistance. The theoretical basis of the method is fully described in previous reports [9, 10].

The 20 tests were conducted on normal subjects. Prior to the GXT, which included the investigational IB measurements, each subject performed standard pulmonary function tests and a standard maximal GXT. For each investigational GXT, six work loads were selected starting at rest and proceeding in similar increments to a goal of $75 \%$ of that subject's maximum $\mathrm{VO}_{2}$. These work loads were equivalent to $31 \%, 42 \%, 53 \%, 64 \%$ and $75 \%$ of the $\mathrm{VO}_{2} \max$. The IB measurements were made at each of these six standardized levels, so that the response to increasing work load could be evaluated with regard to actual work load (expressed as $\mathrm{VO}_{2}$ in liters/min) as well as standardized to each subject's maximum $\mathrm{VO}_{2}$ (expressed as a percentage of maximum $\mathrm{VO}_{2}$ ) [2]. A single IB measurement of $\mathrm{Q}_{\mathrm{C}}$ and $\mathrm{D}_{\mathrm{L}} \mathrm{CO}$ was made during the last minute of a three minute interval at each work level.

The data shown graphically in Fig. (1) were displayed following each test to assure that expiratory flow was steady and $<1$ liter/minute, that dead space had been cleared, and that gas concentrations were stable and measured over the appropriate interval, $25 \%-75 \%$ of the exhaled vital capacity.

\section{Selection of Subjects}

Subjects were recruited from the medical and technical staffs of Mary Immaculate Hospital, Jamaica, NY and reflected their ethnic, age and gender distribution. All subjects considered themselves reasonably fit and active but

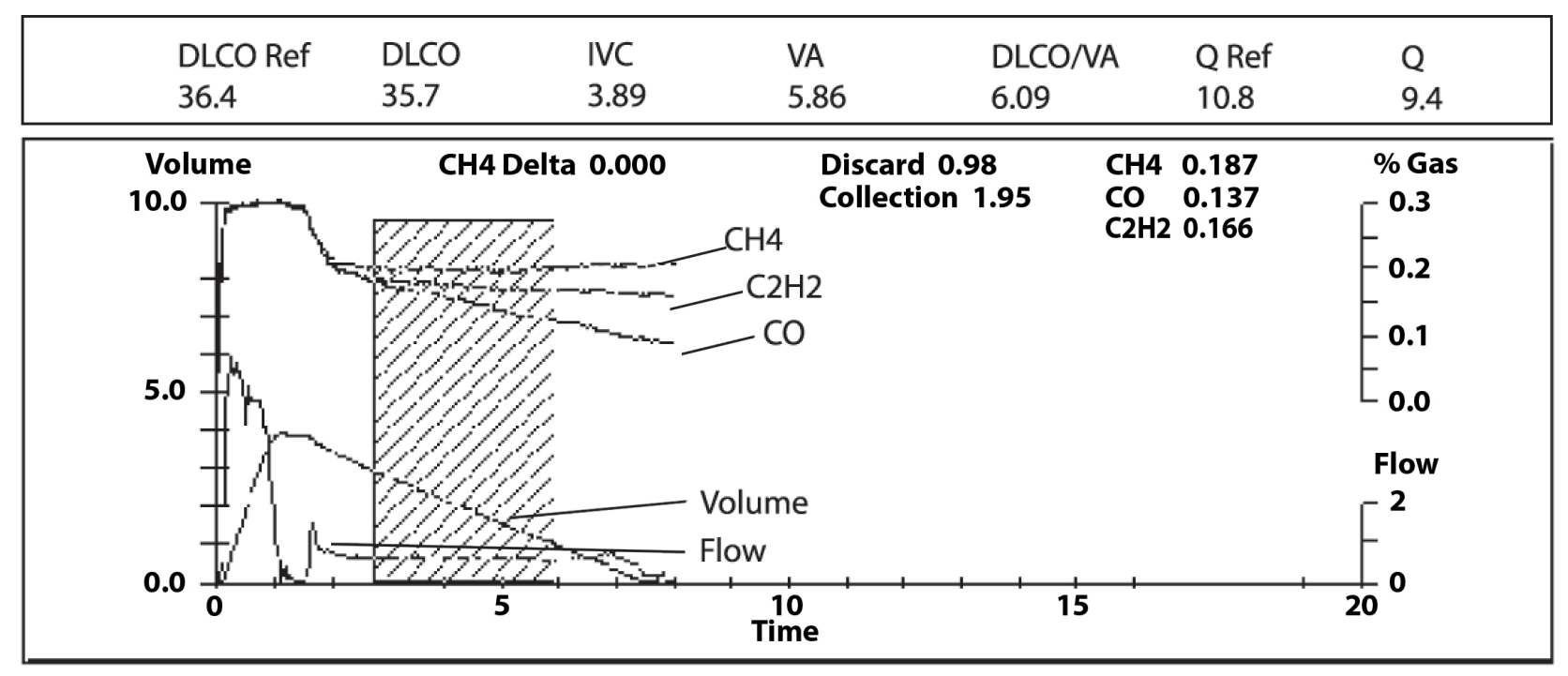

Fig. (1). Intrabreath maneuver. The display depicts a successful Intrabreath maneuver at 60 watts of steady state exercise. $I B-D_{L} C O=35.7$ and $I_{B}-Q_{C}=9.4$. Lung Volume is on the left axis, while the right axis indicates the gas concentrations and expiratory flow rate. The hatched area indicates the period of exhalation selected by the computer for analysis; after discarding 0.98 liters of dead space sample, steady slow exhalation of 1.95 liters over approximately 3.3 seconds was evaluated. Generally, a steady expiratory flow of less than 1 liter per second for a minimum of 3 seconds after clearing dead space is required for a reliable measurement. The operator can override the computer selection. 
not athletic and were free of any significant medical disorder. Informed consent was obtained and the study was conducted under the supervision of the Institutional Review Board of Mary Immaculate Hospital.

\section{Evaluation Methods}

Differences between means of $\mathrm{Q}_{\mathrm{C}}, \mathrm{D}_{\mathrm{L}} \mathrm{CO}$ and $\mathrm{VO}_{2}$ at the six workloads were evaluated using t-tests, pooled or paired as appropriate. Linear regression equations describing the increase of $\mathrm{Q}_{\mathrm{C}}$ and $\mathrm{D}_{\mathrm{L}} \mathrm{CO}$ with exercise were calculated for each patient, and then averaged for the population. Variation among regression responses to exercise were evaluated using $95 \%$ confidence limits. A $p<0.05$ was prospectively defined as statistically significant. Unless indicated otherwise \pm denotes standard deviation. All descriptive and comparative statistics were calculated using either Microsoft Excel (Microsoft Corporation, Redmond WA) or SPSS 11.0 (SPSS, Inc. Chicago, IL).

\section{RESULTS}

The demographics, pulmonary function, and GXT results of the subjects are described in Table 1 . The subjects' ages ranged between 25 and 62 years. Seven of the 20 subjects were female; 11 were of Asian origin. Subjects were of normal height and weight. Their pulmonary function was characterized as low normal $[16,17]$. This is consistent with the ethnicity of a majority of them since many Asian ethnic groups show low normal or slightly decreased values when compared to pulmonary function predicted values for Caucasians. Their fitness was typical of normal unconditioned adults with a maximum $\mathrm{VO}_{2}$ of approximately $27 \mathrm{ml} / \mathrm{min} / \mathrm{kg}$ and a normal anaerobic threshold. Baseline data were complete for all subjects. Only 3 subjects did not complete the appropriate IB expiratory maneuver at one single stage of exercise; this was due to a temporary obstruction in the gas sample line.

Table 1. Characteristics of the 20 Subjects Performing Graded Exercise Tests

\begin{tabular}{|c|c|c|c|}
\hline & Mean & sd & Range \\
\hline Age & 35 & 10 & $25-62$ \\
\hline Gender \% Female & 35 & & \\
\hline Height (cm) & 169 & 9 & $138-163$ \\
\hline Weight (kg) & 72 & 14 & $50-110$ \\
\hline FVC (\% predicted) $[16]$ & 94 & 12 & $78-107$ \\
\hline FEV1 (\% predicted) [16] & 90 & 12 & $74-110$ \\
\hline $\mathrm{D}_{\mathrm{L}} \mathrm{CO}(\%$ predicted $)[17]$ & 95 & 16 & $69-126$ \\
\hline $\mathrm{VO}_{2}-\max (\mathrm{ml} / \mathrm{kg} / \mathrm{min})$ & 27 & 7 & $19-46$ \\
\hline $\mathrm{VO}_{2}-\max (\mathrm{L} / \mathrm{min})$ & 1.96 & 0.66 & $1.11-3.10$ \\
\hline $\mathrm{VO}_{2}-\max (\% \text { predicted })^{2}$ & 76 & 18 & $38-110$ \\
\hline $\mathrm{VO}_{2}-\mathrm{AT}(\mathrm{ml} / \mathrm{kg} / \mathrm{min})$ & 16 & 4 & $10-24$ \\
\hline $\mathrm{VO}_{2}-\mathrm{AT}(\mathrm{L} / \mathrm{min})$ & 1.16 & 0.37 & $.75-1.99$ \\
\hline $\mathrm{VO}_{2}-\mathrm{AT}(\% \text { predicted max })^{2}$ & 46 & 11 & $22-69$ \\
\hline HR max & 167 & 14 & $150-194$ \\
\hline
\end{tabular}

The results of the investigational GXT for the six stages of exercise are described in Table 2. The tests covered a range from rest $\left(\mathrm{VO}_{2}=0.35 \pm 0.11 \mathrm{~L} / \mathrm{min}\right)$ to $76 \% \pm 13 \%$ of maximum $\left(\mathrm{VO}_{2}=1.43 \pm 0.38 \mathrm{~L} / \mathrm{min}\right)$. There was a statistically significant increase in $\mathrm{VO}_{2}(\mathrm{p}<0.001)$ and pulmonary capillary blood flow $(\mathrm{p}<0.05)$ between each successive stage of exercise. The increase in lung diffusion was significant $(p<0.05)$ between all the stages except $2 \& 3$ and $4 \& 5$.

Table 2. Graded Exercise Test Results at Six Workloads

\begin{tabular}{|c|c|c|c|c|c|c|}
\hline Stage & Rest & 2 & 3 & 4 & 5 & 6 \\
\hline \multicolumn{7}{|c|}{$\% \mathrm{VO}_{2} \max$} \\
\hline mean & 19 & 32 & 43 & 55 & 64 & 76 \\
\hline $\mathrm{sd}$ & 5 & 9 & 9 & 12 & 14 & 13 \\
\hline \multicolumn{7}{|c|}{$\mathrm{VO}_{2}(\mathrm{~L} / \mathrm{min})$} \\
\hline mean & 0.35 & 0.59 & 0.81 & 1.02 & 1.20 & 1.43 \\
\hline $\mathrm{sd}$ & 0.11 & 0.16 & 0.20 & 0.25 & 0.32 & 0.38 \\
\hline \multicolumn{7}{|c|}{$\mathrm{VO}_{2}(\mathrm{ml} / \mathrm{kg} / \mathrm{min})$} \\
\hline mean & 5.0 & 8.4 & 11.4 & 14.4 & 16.9 & 20.2 \\
\hline sd & 1.7 & 2.1 & 2.5 & 3.0 & 3.5 & 4.3 \\
\hline \multicolumn{7}{|c|}{ IB-Q $Q_{C}(L / m i n)$} \\
\hline mean & 5.3 & 7.7 & 8.5 & 9.9 & 10.7 & 12.4 \\
\hline $\mathrm{sd}$ & 1.5 & 2.2 & 1.9 & 2.1 & 2.5 & 3.1 \\
\hline \multicolumn{7}{|c|}{ IB-D $\mathrm{L}_{\mathrm{L}} \mathrm{CO}(\mathrm{ml} / \mathrm{mmHg} / \mathrm{min})$} \\
\hline mean & 21.5 & 25.5 & 26.5 & 29.1 & 30.5 & 32.3 \\
\hline $\mathrm{sd}$ & 4.9 & 7.3 & 7.6 & 7.9 & 8.2 & 9.1 \\
\hline
\end{tabular}

$\mathrm{IB}_{\mathrm{C}} \mathrm{Q}_{\mathrm{C}}=$ intrabreath pulmonary capillary blood flow, $\mathrm{IB}-\mathrm{D}_{\mathrm{L}} \mathrm{CO}=$ intrabreath lung diffusion, $\mathrm{sd}=$ standard deviation.

The pulmonary capillary blood flow $\left(\mathrm{Q}_{\mathrm{C}}\right)$ of the group increased more than two-fold from baseline values $(95 \%$ confidence limits: $205 \%$ - 277\%). The $\mathrm{Q}_{\mathrm{C}}$ response to increased exercise, as determined by linear regression, was:

$\mathrm{Q}_{\mathrm{C}}(\mathrm{L} / \mathrm{min})=3.5+6.5 * \mathrm{VO}_{2}(\mathrm{~L} / \mathrm{min}),(\mathrm{r}=.81)$

The lung diffusion increased about $50 \%$ above baseline ( $95 \%$ confidence limits: $139 \%-163 \%$ ). The $\mathrm{D}_{\mathrm{L}} \mathrm{CO}$ response to increased exercise, as determined by linear regression, was:

$\mathrm{D}_{\mathrm{L}} \mathrm{CO}(\mathrm{ml} / \mathrm{mmHg} / \mathrm{min})=18.7+10.2 * \mathrm{VO}_{2}(\mathrm{~L} / \mathrm{min}),(\mathrm{r}=.84)$

Non linear regression did not improve the correlation for either parameter. There was no statistically significant difference in the regression with regard to gender, allowing pooling of the data. The standard error of the response to exercise (i.e., slope) for $\mathrm{Q}_{\mathrm{C}}$ and $\mathrm{D}_{\mathrm{L}} \mathrm{CO}$ was $0.6 \mathrm{~L} / \mathrm{min}$ and 1.2 $\mathrm{ml} / \mathrm{mmHg} / \mathrm{min}$ respectively.

Because only one measurement of $\mathrm{Q}_{\mathrm{C}}$ and $\mathrm{D}_{\mathrm{L}} \mathrm{CO}$ could be made at each work load, we evaluated the reliability of individual measurements by comparing each of the six measurements to the regression for that subject. The mean variation from the regression for $\mathrm{Q}_{\mathrm{C}}$ and $\mathrm{D}_{\mathrm{L}} \mathrm{CO}$ were 
$9.9 \% \pm 4.6 \%$ and $6.6 \% \pm 3.6 \%$ respectively. We also evaluated these differences to determine how many individual measurements were excessively deviant from the regression. Excessive deviation was defined to be $20 \%$ or 2 $\mathrm{L} / \mathrm{min}$ for $\mathrm{Q}_{\mathrm{C}}$ and $20 \%$ or $5 \mathrm{ml} / \mathrm{mmHg} / \mathrm{min}$ for $\mathrm{D}_{\mathrm{L}} \mathrm{CO}$, whichever was larger. Only 4 measurements of both responses $(<4 \%$ of the total) met the criteria for excessive deviation.

The increase above resting levels for both $\mathrm{Q}_{\mathrm{C}}$ and $\mathrm{D}_{\mathrm{L}} \mathrm{CO}$ across the range of workloads (expressed as $\mathrm{VO}_{2} \mathrm{~L} / \mathrm{min}$ ) can be seen in Fig. (2). At a moderate workload expressed in $\mathrm{VO}_{2}$ as liters/minute $\left(\mathrm{VO}_{2}=1.0 \mathrm{~L} / \mathrm{m}\right)$, the $\mathrm{D}_{\mathrm{L}} \mathrm{CO}$ is expected to increase to at least $120 \%$ of resting level and the $\mathrm{Q}_{\mathrm{C}}$ to at least $165 \%$ of the resting level. The increase above resting levels for both $\mathrm{Q}_{\mathrm{C}}$ and $\mathrm{D}_{\mathrm{L}} \mathrm{CO}$ across the range of workloads expressed as a percentage of maximum $\mathrm{VO}_{2}$, can be seen in Fig. (3). At $50 \%$ of maximum $\mathrm{VO}_{2}, \mathrm{D}_{\mathrm{L}} \mathrm{CO}$ can be expected to increase to at least $120 \%$ of resting level and $\mathrm{Q}_{\mathrm{C}}$ can be expected to increase to at least $160 \%$ of the resting level.

\section{DISCUSSION}

Previous studies of exercise response in cardiac output and lung diffusion have used various methods to measure these variables. Several have made these measurements at a single level of exercise characterized by heart rate alone [14, 18]. The intrabreath (IB) technique is well suited to making these measurements during progressive exercise, since it requires only a single deep breath and does not require a fixed breath hold. Its development has been made practical by economical rapid infra-red gas analyzers and increasing computational power, both required for the continuous measurements and complex calculations. It is now available as an option in a standardized commercial instrument.

We made $\mathrm{Q}_{\mathrm{C}}$ and $\mathrm{D}_{\mathrm{L}} \mathrm{CO}$ measurements at 6 stages of exercise ranging from rest to an average of $76 \%$ of each subject's maximum in GXT's in 20 normal subjects. Increases in these measurements reflect the ability of the pulmonary capillaries to distend and recruit during exercise.

We found the $\mathrm{Q}_{\mathrm{C}}$ response to increased exercise to be: $\mathrm{Q}_{\mathrm{C}}$ $(\mathrm{L} / \mathrm{min})=3.5+6.5 * \mathrm{VO}_{2}(\mathrm{~L} / \mathrm{min})$. This is consistent with the literature. In 1962 Wade and Bishop characterized the normal response of cardiac output to exercise by a linear increase with increased work, defined by the equation cardiac output $(\mathrm{L} / \mathrm{min})=4+6 * \mathrm{VO}_{2}(\mathrm{~L} / \mathrm{min})( \pm 2 \mathrm{~L} / \mathrm{min}$ SEE) [19]. Others have suggested normalization for weight (cardiac output $(\mathrm{L} / \mathrm{min})=.06 * \mathrm{wt}(\mathrm{kg})+5 * \mathrm{VO}_{2}( \pm 1 \mathrm{~L} / \mathrm{min})$ [2].

The increase in $\mathrm{Q}_{\mathrm{C}}$ in our normal subjects using the IB technique during progressive exercise is similar to the increases reported by previous investigators using the rebreathing or IB techniques and different exercise increments. Hsia and coworkers [20] have reported both $\mathrm{Q}_{\mathrm{C}}$ and $\mathrm{D}_{\mathrm{L}} \mathrm{CO}$ (see below) using a rebreathing method in 44 normal subjects at $25 \%, 50 \%$ and $80 \%$ of each individual's maximum workload. At $80 \%$ of maximum, $\mathrm{Q}_{\mathrm{C}}$ increased $134 \%$ in males and $100 \%$ in females. The magnitude was similar in our study, although we did not note a difference between genders. Wilson [9], using the IB technique at various steady state exercise levels separated by return to baseline in 10 normal subjects, reported $\mathrm{Q}_{\mathrm{C}}(\mathrm{L} / \mathrm{min})=5.2+$ $5.1 * \mathrm{VO}_{2}(\mathrm{~L} / \mathrm{min}) \pm(1.7 \mathrm{~L} / \mathrm{min} \mathrm{SEE})$, very similar to our $\mathrm{Q}_{\mathrm{C}} / \mathrm{VO}_{2}$ relationship. Huang, MacIntyre and coworkers [14] have used the IB method at a single level of exercise. At a level similar to our stage 4 (which is $55 \%$ of maximum $\mathrm{VO}_{2}$ ), they reported $\mathrm{Q}_{\mathrm{C}}$ increases of $89 \%$ for 30 year old men and $102 \%$ for 30 year old women, very similar to the $87 \%$ we reported for both sexes with an average age of 36 years. More recently, Blevins and coworkers [15], using the Intrabreath technique for $\mathrm{Q}_{\mathrm{C}}$, reported similar regressions for $\mathrm{Q}_{\mathrm{C}} v s \mathrm{VO}_{2}$ to ours and noted that these were stable over time

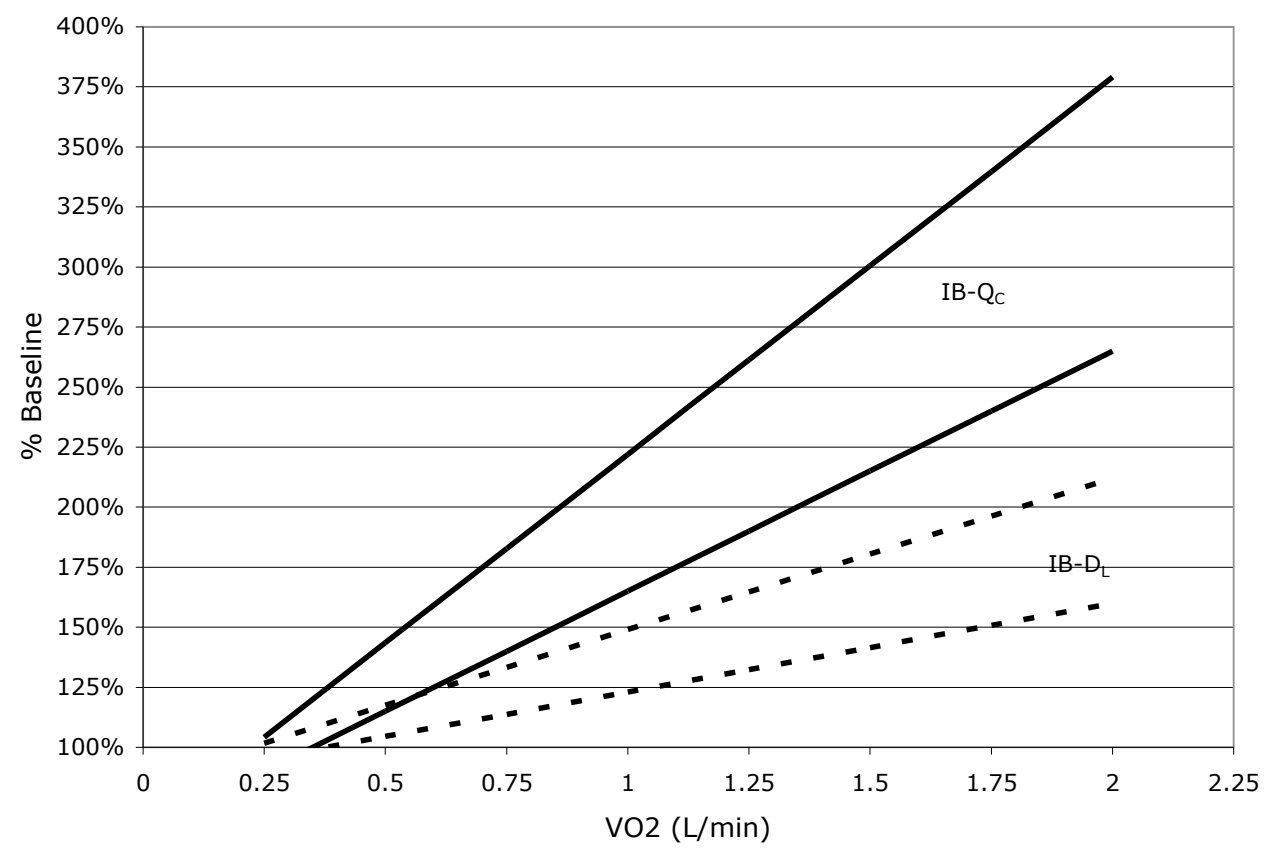

Fig. (2). Response to Exercise $\left(\mathrm{VO}_{2} ; \mathrm{L} / \mathrm{min}\right)$. The upper two solid lines describe the $95 \%$ SEE boundaries of the cardiac output (IB-Q $)$ response above baseline to increasing exercise. The bottom two dashed lines describe the $95 \% \mathrm{SEE}$ for lung diffusion (IB- $\mathrm{D}_{\mathrm{L}} \mathrm{CO}$ ) response to increasing exercise. 


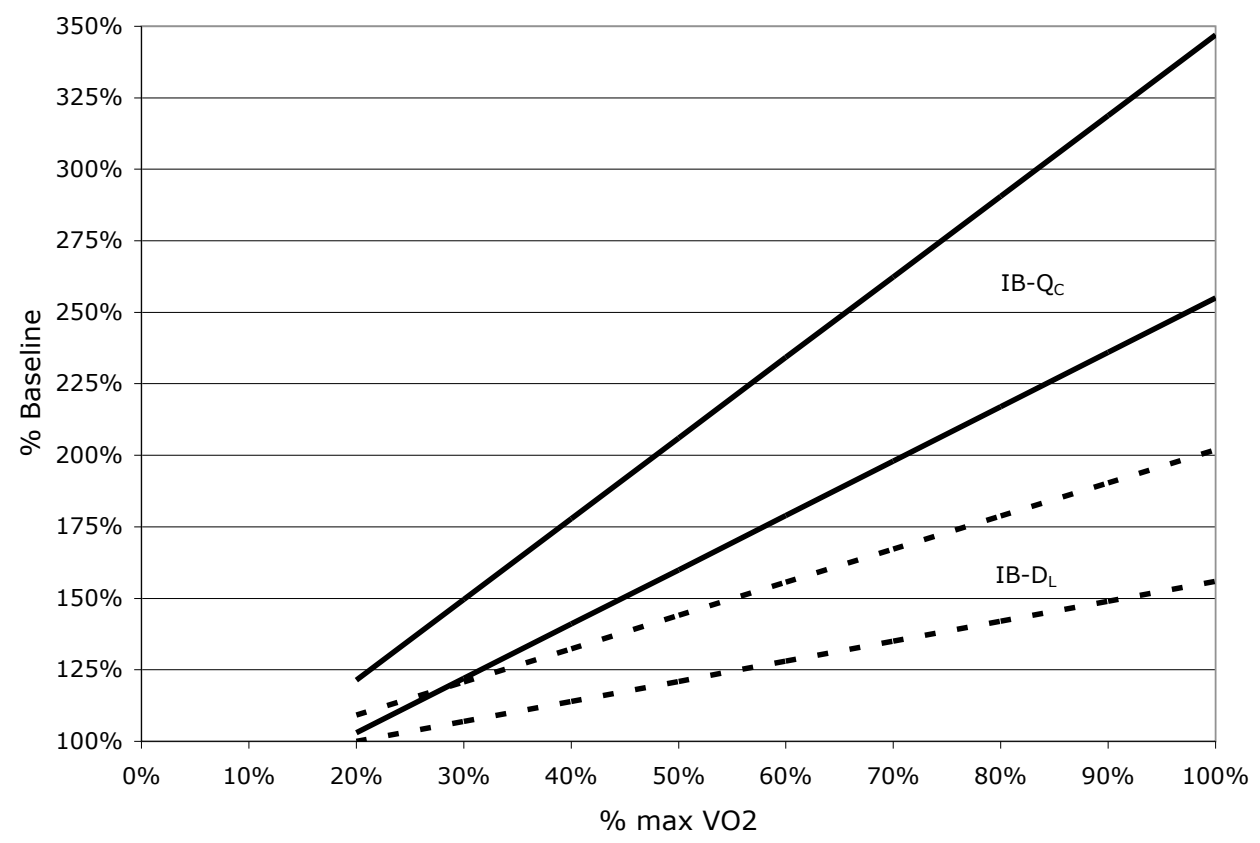

Fig. (3). Response to Exercise (\% max $\mathrm{VO}_{2}$ ). The upper two solid lines describe the $95 \%$ SEE boundaries of the cardiac output (IB-Q $\mathrm{Q}_{\mathrm{C}}$ ) response above baseline to increasing exercise. The bottom two dashed lines describe the $95 \% \mathrm{SEE}$ for lung diffusion (IB- $\mathrm{D}_{\mathrm{L}} \mathrm{CO}$ ) response to exercise.

and technique (fixed load vs ramp). They did not measure $\mathrm{D}_{\mathrm{L}} \mathrm{CO}$.

In patients with cardiac disease, a blunted response to exercise (i.e., less than normal increase with exercise) has been found to be prognostic. In a series of 46 postmyocardial infarction patients, Bigi found that a blunted cardiac output response to exercise at discharge was a better indicator of cardiovascular risk than ECG changes [7]. In a study of 185 heart failure patients using thermal dilution, Chomsky identified the strong independent prognostic value of a blunted cardiac output response to exercise [5]. Resting $\mathrm{D}_{\mathrm{L}} \mathrm{CO}$ is decreased in heart failure [21], attributable to decreased $\mathrm{D}_{\mathrm{m}}$; both $\mathrm{D}_{\mathrm{L}}$ and $\mathrm{D}_{\mathrm{m}}$ correlated with $\mathrm{VO}_{2} \mathrm{max}$ and inversely with pulmonary vascular resistance.

In our subjects, we found the average $\mathrm{D}_{\mathrm{L}} \mathrm{CO}$ response to progressive exercise, determined with linear regression to be: $\mathrm{D}_{\mathrm{L}} \mathrm{CO}(\mathrm{ml} / \mathrm{mmHg} / \mathrm{min})=18.7+10.2 * \mathrm{VO}_{2}(\mathrm{~L} / \mathrm{min})$. Hsia et al. [20], using the rebreathing method, reported increases of $65 \%$ in men and $26 \%$ in women at $80 \%$ of maximum $\mathrm{VO}_{2}$, within a range similar to our results. In three normal subjects, reported by Potts and coworkers, increases in $\mathrm{D}_{\mathrm{L}} \mathrm{CO}$ measured by the three equation method at $90 \%$ of peak exercise, ranged from $61 \%$ to $75 \%$, consistent with our regression for this somewhat greater level of exercise [22]. Wilson et $a l$, in a study of 10 fit individuals with the IB technique, reported somewhat higher values at lower levels of exercise, but not as much of a percent increase with increasing exercise. $\left(\mathrm{D}_{\mathrm{L}} \mathrm{CO}(\mathrm{ml} / \mathrm{mmHg} / \mathrm{min})=34+7 * \mathrm{VO}_{2}\right.$ $(\mathrm{L} / \mathrm{min})$ ) [13]. However, one of their ten subjects, who was the only female and significantly older and less fit, attained levels similar to that seen in our group. Table $\mathbf{2}$ shows that at $55 \%$ of maximum $\mathrm{VO}_{2}, \mathrm{D}_{\mathrm{L}} \mathrm{CO}$ in our subjects (mean age 36 years) increased $35 \%$ from baseline. Consistent with the results in our population, Haung et al. reported a predicted increase of approximately $30 \%$ in $\mathrm{D}_{\mathrm{L}} \mathrm{CO}$ from rest to an exercise level of $58 \%$ of the predicted maximum heart rate, in their study of 100 normal subjects using the IB technique [18]. The predicted increase for a 30 year old male was $33 \%$ and for a 30 year old female $24 \%$. These investigators recently reported slightly lower increases in a slightly older study population (mean 40 age years). This increase was $29 \%$ in 56 men and $18 \%$ in 49 women [17]. Again, we did not observe a gender difference. Kendrick and Laszlo [26] Studied 80 normal subjects evenly distributed by sex and age (from 20-59) and concluded that the rate of increase in $\mathrm{D}_{\mathrm{L}} \mathrm{CO}$ with increasing exercise is not affected by age and is slightly less in females.

Recent investigators have compared DL for nitric oxide with that for $\mathrm{CO}$ during incremental exercise, noting a linear increase in both and a constant ratio for the two measurements $[23,24]$. Since $\mathrm{D}_{\mathrm{L}} \mathrm{NO}$ is not limited by pulmonary capillary blood volume, it is equal to $\mathrm{D}_{\mathrm{M}}$.

Both $\mathrm{D}_{\mathrm{L}} \mathrm{CO}$ and $\mathrm{D}_{\mathrm{L}} \mathrm{NO}$ decrease at 2 hours after maximal exercise (to exhaustion) [25], unlike their linear increase during progressive submaximal exercise.

Failure to increase $\mathrm{D}_{\mathrm{L}} \mathrm{CO}$ during exercise has been reported in a few studies to reflect subclinical pulmonary impairment. Using the IB technique, Mitchell and coworkers found that, in a group of 30 seven year old children, survivors of bronchopulmonary dysplasia were unable to increase $\mathrm{D}_{\mathrm{L}} \mathrm{CO}$ above resting levels at moderate exercise despite modest increases in $\mathrm{Q}_{\mathrm{C}}$ [27]. This inability to increase $\mathrm{D}_{\mathrm{L}} \mathrm{CO}$ was not seen in either of their control groups of former preterm or term infants. In adults, a recent study noted significantly increased post-operative morbidity associated with failure to improve lung diffusion by more that $10 \%$ from rest to high levels of exercise in pre-surgical lung resection patients [6]. Reduction of $\mathrm{D}_{\mathrm{L}} \mathrm{CO}$ as a consequence of chronic pulmonary hypertension has been 
identified as an important factor in the limitation of peak exercise in patients with heart failure [21].

Individual intrabreath $\mathrm{D}_{\mathrm{L}} \mathrm{CO}$ and $\mathrm{Q}_{\mathrm{C}}$ measurements have considerable variability. Similar variability is found in cardiac output measured by other techniques during exercise. Average coefficient of variations of $\mathrm{Q}_{\mathrm{C}}$ of $8.7 \%$ and $12 \%$ using the intrabreath method at rest were reported by Elkayam [10] and Blevins [15]. This is comparable to our experience during exercise, an average deviation from the regression of $9.9 \%$ and $6.6 \%$ for $\mathrm{Q}_{\mathrm{C}}$ and $\mathrm{D}_{\mathrm{L}} \mathrm{CO}$ respectively. We also found that less than $4 \%$ of the individual measurements were excessively deviant. Unfortunately only a single IB measurement of $\mathrm{D}_{\mathrm{L}} \mathrm{CO}$ and $\mathrm{Q}_{\mathrm{C}}$ can be made at each level of exercise when using incremental protocols with stages of 3 minutes or less. Variability can be addressed in two ways. It can be averaged out by looking at the trend in repeated single measurements with increasing exercise as was done in this study or by averaging repeated measurements at fewer more prolonged workloads. Some bias will exist between the IB $Q_{C}$, which measures unshunted pulmonary blood flow, and true cardiac output. This bias should be considered in evaluating the results in abnormal populations with the potential for intra cardiac and pulmonary shunts.

We presented our $\mathrm{D}_{\mathrm{L}} \mathrm{CO}$ and $\mathrm{Q}_{\mathrm{C}}$ results in three different metrics. The first approach presented the actual $\mathrm{D}_{\mathrm{L}} \mathrm{CO}$ and $\mathrm{Q}_{\mathrm{C}}$ values increasing as a function of the metabolic workload $\left(\mathrm{VO}_{2} \mathrm{~L} / \mathrm{min}\right)$. The other two approaches compared percentage increases from baseline in $\mathrm{D}_{\mathrm{L}} \mathrm{CO}$ and $\mathrm{Q}_{\mathrm{C}}$ with incremental exercise to absolute workload $\left(\mathrm{VO}_{2} \mathrm{~L} / \mathrm{min}\right)$ and to percent of individual maximum. The latter approach was undertaken to adjust for differences in exercise capacity associated with age, size and gender. Use of response above baseline, while appealing, is limited by the need for careful baseline measurement.

Based on these limitations it would appear that assessment of the slope of the response to exercise $\left(\mathrm{Q}_{\mathrm{C}} / \mathrm{VO}_{2}\right.$ and $\mathrm{D}_{\mathrm{L}} \mathrm{CO} / \mathrm{VO}_{2}$ ) would be the most useful approach to interpretation. This approach is well suited to making single repeated measurements during an incremental GXT as used in this investigation and by Chomsky [5] or at several levels of steady state exercise as advocated by Jones [2]. Alternatively measurements at rest and at one level of moderate exercise might be used as a simple assessment of response in these variables. Our data show that $\mathrm{D}_{\mathrm{L}} \mathrm{CO}$ increased by at least $20 \%$ and $\mathrm{Q}_{\mathrm{C}}$ by at least $50 \%$ from resting levels at $50 \%$ of maximum, suggesting that we can apply these guidelines to simplify exercise testing. These findings are consistent with the two studies by the Duke group $[15,18]$. Using measured $\mathrm{VO}_{2}$ rather than percentage maximum, similar increases can be expected at $0.9 \mathrm{~L} / \mathrm{min}$ $\mathrm{VO}_{2}$. Several measurements can be made at such a workload to eliminate an aberrant value. Furthermore, these workloads are generally below the anaerobic threshold and thus easily tolerated by most subjects.

\section{CONCLUSIONS}

We found the intrabreath procedure easy to integrate into our clinical GXT. Furthermore our results with normal volunteers during incremental exercise, a methodology well suited to clinical practice, were consistent with published expectations from research protocols using steady state exercise requiring multiple days to complete. Our findings are acceptably reliable to use for clinical reference. While a strong physiological rationale supports the likely prognostic potential of these measurements, there is a paucity of clinical data. We intend, and recommend to others, to include these measurements in the standard diagnostic GXT so that information on pulmonary blood flow and lung diffusion response to exercise in various abnormal populations can be fully characterized.

\section{CONFLICT OF INTEREST}

Statistical analysis was supported by VIASYS Healthcare Corporation, Yorba Linda CA through a grant to Mr. Bachman.

\section{REFERENCES}

[1] Wasserman K, Whipp B. Exercise physiology in health and disease. Am Rev Respir Dis 1975; 112: 219-49.

[2] Jones N. Clinical exercise testing. 4th ed. Philadelphia PA: WB Saunders Company 1997.

[3] Miller A, Bhuptani A, Sloane MF, Brown LK, Teirstein AS Cardiorespiratory responses to incremental exercise in patients with asbestos-related pleural thickening and normal or near normal lung function. Chest 1993; 103: 1045-50.

[4] Miller A, Brown LK, Sloane MF, Bhuptani A, Teirstein AS Cardiorespiratory responses to incremental exercise in sarcoidosis patients with normal spirometry. Chest 1995; 107: 323-29.

[5] Chomsky D, Lang C, Rayos G, et al. Hemodynamic exercise testing, a valuable tool in the selection of cardiac transplant candidates. Circulation 1996; 94: 3176-83.

[6] Wang JS, Abboud RT, Evans KG, Finley RJ, Graham BL. Role of diffusing capacity during exercise in preoperative evaluation for lung resection. Am J Respir Crit Care Med 2000; 162: 1435-44.

[7] Bigi R, Desideri A, Rambaldi R, Cortigiani L, Sponzilli C, Fiorentini C. Angiographic and prognostic correlates of cardiac output by cardiopulmonary exercise testing in patients with anterior myocardial infarction. Chest 2001; 120:825-33.

[8] Williams SG, Cooke GA, Wright DJ, et al. Peak exercise cardiac power output; a direct indicator of cardiac function strongly predictive of prognosis in chronic heart failure. Eur Heart J 2001; 22: 1496-03.

[9] Wilson AF, Savariryan S, James N, Mukai D, Nishimura E. Almost simultaneous measurement of cardiovascular and gas exchange variables during maximal exercise. Med Sci Sports Exer 1996; 28: 436-43.

[10] Elkayam U, Wilson A, Morrison J, et al. Non-invasive measurement of cardiac output by a single breath constant expiratory technique. Thorax 1984; 39: 107-13.

[11] Zenger M, Brenner M, Haruno M, Mahon D, Wilson A. Measurement of cardiac output by an automated single breath technique and simultaneous comparison with thermal dilution and Fick methods in cardiac patients. Am J Cardiol 1993; 71:105-9.

[12] Sadeh JS, Miller A, Kukin M. Noninvasive measurement of cardiac output by acetylene uptake technique and simultaneous comparison with thermal dilution in ICU patients. Chest 1997; 111: 1295-300.

[13] Ramage JE Jr, Coleman RE, MacIntyre NR. Rest and exercise cardiac output and diffusing capacity assessed by a single slow exhalation of methane, acetelyne and carbon monoxide. Chest 1987; 92:44-50.

[14] Huang YT, Helms MJ, MacIntyre NR. Normal values for single exhalation diffusing capacity and pulmonary capillary blood flow in sitting, supine positions and during mild exercise. Chest 1994; 105: 501-8.

[15] Blevins JS, Herbert WG, Zedalis D, Cross L. Reliability of a single-breath acetylene cardiac output technique during exercise: ramping $v s$ fixed load protocols. Am J Med Sports 2003; 5: 256-61.

[16] Miller A, Thornton JC, Warshaw R, Bernstein J, Teirstein AS, Selikoff IJ. Mean and instantaneous expiratory flows, FVC and FEV1: prediction equations for non smokers and smokers from a 
random sample of Michigan, a large industrial state. Bull Physiopath Respir 1986; 22: 589-97.

[17] Miller A, Thornton JC, Warshaw R, Anderson H, Selikoff IJ, Teirstein AS. Single breath diffusing capacity in a representative sample of the population of Michigan, a large industrial state: predicted values, lower limits of normal, frequencies of abnormality by smoking history. Am Rev Respir Dis 1983; 127; 270-77.

[18] Huang YT, O'Brien SR, MacIntyre NR. Intrabreath diffusing capability of the lung in healthy individuals at rest and during exercise. Chest 2002; 122: 177-85.

[19] Wade OL, Bishop JM. Cardiac output and regional blood flow. FA Davis Philadelphia: Blackwell Scientific Publication 1962.

[20] Hsia CW, McBrayer DG, Ramanathan M. Reference values of pulmonary diffusing capacity during exercise by a rebreathing technique. Am J Respir Crit Care Med 1995; 152: 658-65.

[21] Puri S, Baker BL, Dutka DP, Oakley CM, Hughes JMB, Cleland JGF. Reduced alveolar-capillary membrane diffusing capacity in chronic heart failure: its pathophysiological relevance and relationship to exercise performance. Circulation 1995; $91: 2769$ 74.

[22] Potts J, Abboud R, Graham B. The use of the three equation method to measure $\mathrm{D}_{\mathrm{L}} \mathrm{CO}_{\mathrm{SB}}$ during exercise in normal healthy adults. Am J Respir Crit Care Med 1996; 153: A650 [abstract].

[23] Zavorsky GS, Quiron KB, Massarelli PS, et al. The relationship between single-breath diffusion capacity of the lung for nitric oxide and carbon monoxide during various exercise intensities. Chest 2004; 125: 1019-27.

[24] Borland C, Mist B, Zammit M, Vuylsteke A. Steady-state measurement of $\mathrm{NO}$ and $\mathrm{CO}$ lung diffusing capacity on moderate exercise in men. J Appl Physiol 2001; 90: 538-44.

[25] Zavorsky GS, Lands LC. Lung diffusion capacity for nitric oxide and carbon monoxide is impaired similarly following short-term graded exercise. Nitric Oxide 2005; 12: 31-8.

[26] Kendrick AH, Laszlo G. CO Transfer factor on exercise: age and sex differences. Eur Respir J 1990; 3: 323-8.

[27] Mitchell S, Teague W. Reduced gas transfer at rest and during exercise in school aged survivors of bronchopulmonary dysplasia. Am J Respir Crit Care Med 1998; 157: 1406-12.

(C) Miller et al.; Licensee Bentham Open.

This is an open access article licensed under the terms of the Creative Commons Attribution Non-Commercial License (http://creativecommons.org/licenses/by-nc/3.0/) which permits unrestricted, non-commercial use, distribution and reproduction in any medium, provided the work is properly cited. 